\title{
ANÁLISE DO CARÁTER PROFISSIONALIZANTE DOS CURSOS TÉCNICOS DO IFMG - CAMPUS AVANÇADO ITABIRITO ${ }^{1}$
}

\author{
Cleverson Faria de Oliveira ${ }^{2}$ \\ Cláudia Rejane de Mesquita \\ Venilson Luciano Benigno Fonseca
}

\begin{abstract}
RESUMO
Este artigo tem por objetivo apresentar resultados de uma pesquisa de campo realizada com exalunos dos cursos técnicos ofertados pelo IFMG - Campus Avançado Itabirito referente ao caráter profissionalizante desses cursos. A motivação dessa pesquisa é resultado de uma percepção dos autores, desenvolvida na atuação docente nos cursos técnicos, no que diz respeito à baixa procura por estágio de nível técnico e o ingresso imediato em cursos superiores. Dessa forma, a pesquisa de campo realizada buscou o levantamento de números e das principais razões apontadas pelos ex-alunos na escolha por eles tomadas. A análise dos resultados mostra que apesar da maioria dos ex-alunos discordarem da obrigatoriedade do Estágio Supervisionado, muitos deles entendem que o estágio é uma atividade muito importante na formação e na empregabilidade e apontam justificativas para a não procura por estágio durante a realização do curso ou após sua conclusão, já que o componente estágio supervisionado é optativo na grade curricular. A pesquisa também evidenciou o alto grau de interesse pela continuidade na formação acadêmica-profissional, bem como a diversidade de áreas de interesses, agrupadas aqui em três grupos: tecnologia, humanas e saúde. Apesar dessa diversidade observou-se uma tendência maior pelo prosseguimento da formação nas áreas correlatas ao curso. Ao final do artigo são apresentadas análises reflexivas sobre os resultados encontrados e são traçadas propostas que visam ampliar o interesse e condições para realização de estágio na expectativa de contribuir na melhoria da capacitação técnica profissionalizante de nível médio dos estudantes.
\end{abstract}

Palavras-chave: Estágio supervisionado. Empregabilidade. Profissionalizante.

\section{ANALYSIS OF THE PROFESSIONAL FEATURE OF THE TECHNICAL COURSES OF IFMG - CAMPUS AVANÇADO ITABIRITO}

\begin{abstract}
This paper aims to present results of a field research carried out with former students of

\footnotetext{
${ }^{1}$ Como citar este artigo: OLIVEIRA, C. F.; MESQUITA, C. R.; FONSECA, V. L. B. Análise do caráter profissionalizante dos cursos técnicos do IFMG - Campus Avançado Itabirito. ForScience, Formiga, v. 9, n. 1, e00874, jan./jun. 2021. DOI: 10.29069/forscience.2021v9n1.e874.

${ }^{2}$ Autor para correspondência: Cleverson Faria de Oliveira, e-mail: cleverson.oliveira@ifmg.edu.br.
} 
technical courses offered by the IFMG - Campus Avançado Itabirito regarding the professional feature of courses. The motivation for this research is due to the authors' perception, developed by teaching in technical courses, with regard to the low demand for technical level internships and the immediate entry into higher education courses. Thus, the research aimed to show the numbers and the main reasons pointed out by the former students in their choice. The analysis of the results shows that although most alumni disagree with the mandatory supervised internship to conclude the secondary education, many of them understand that the internship is a very important activity in their professional qualification and employability. They point out justifications for not search for internship during the course or after its conclusion, since the supervised internship component is optional in the curriculum. The research also showed a high level of interest in continuing academic and professional education, as well as the diversity of interest areas, classified into three groups: technology, humanities and health. Despite this diversity, there was a trend towards to the higher education in areas related to the technical course. Finally, this paper presents reflective analyzes of results and proposals are given in order to provide the expansion of interest and conditions for conducting an internship. In this way, there is an expectation of contributing to the improvement of the technical and professional qualification of the technical high school students.

Keywords: Supervised Internship. Employability. Professionalizing.

\section{INTRODUÇÃO}

É notória a dificuldade que os jovens técnicos estão enfrentando para se inserirem no mercado de trabalho. Com a recessão econômica sofrida pelo Brasil na última década e a necessidade dos profissionais terem que trabalhar por mais tempo até se aposentarem, a barreira de entrada para o mercado para os jovens profissionais fica cada vez maior (CASTRO; PONTE, 2019). Além disso, no segundo trimestre de 2017, entre todos os desempregados entre 18 e 24 anos, apenas $25 \%$ conseguiram se inserir no mercado e $57 \%$ estavam a mais de um ano desempregados (CARDOSO, 2018).

Presume-se que o desenvolvimento do país esteja atrelado à formação de profissionais de nível técnico e nível superior de alta qualidade. Dessa forma, em busca de uma formação integrada cada vez mais eficaz, espera-se, por meio deste presente trabalho, suscitar discussões a respeito de possíveis alterações no plano pedagógico dos cursos técnicos a fim possibilitar que a atividade de estágio passe a ser um componente curricular obrigatório. Ou, se não for possível a obrigatoriedade, ao menos favorecer a realização do estágio pelos alunos por meio de adequações na carga horária dos cursos, seja na redistribuição ou redução da carga horária de maneira estratégica para motivar os alunos a realizarem o estágio. Haja vista que o estágio trata-se de uma atividade que complementa essencialmente a formação do aluno não somente na prática do ofício, mas torna possível o amadurecimento no convívio em grupo, na troca de experiências e nas ações inerentes à cultura do trabalho. 
Nesse sentido, tomando como justificativa os fatos relatados acima, este trabalho tem como objetivo investigar o caráter profissionalizante dos cursos de nível técnico do IFMG Campus Avançado Itabirito. Para isso, foi realizada uma pesquisa de campo com os ex-alunos dos cursos técnicos ofertados pelo IFMG.

\section{REFERENCIAL TEÓRICO}

Sabe-se que a integração de conhecimentos no currículo de um curso médio integrado é algo a ser valorizado e perseguido. Ramos (2014) apresenta alguns pressupostos que as instituições devem considerar ao elaborar o projeto político-pedagógico do ensino médio integrado e destaca alguns pontos fundamentais que corroboram no processo de integração. Em síntese, são identificados dois dos principais pressupostos que auxiliam na temática abordada neste presente trabalho:

Não reduzir a educação às necessidades do mercado de trabalho, mas não ignorar as exigências da produção econômica, como campo de onde os sujeitos sociais retiram os meios de vida. Em consequência, é importante considerar os estudos locais, a identificação das oportunidades ocupacionais, as tendências da dinâmica socioprodutiva local, regional, nacional e global. [...] (RAMOS, 2014, p. 101).

$\mathrm{e}$

[...] Tanto os processos de ensino-aprendizagem, como os de elaboração curricular devem ser objeto de reflexão e de sistematização do conhecimento através das disciplinas básicas e do desenvolvimento de projetos que articulem o geral e o específico, a teoria e a prática dos conteúdos, inclusive com o aproveitamento de aprendizagens que os ambientes de trabalho podem proporcionar (visitas, estágios etc.) $[\ldots]$ (RAMOS, 2014, p. 101).

Com o objetivo de facilitar as análises resultantes da pesquisa de campo realizada, julgase importante trazer como considerações básicas as definições de Empregabilidade e de Estágio.

\subsection{Empregabilidade}

Existem diversas interpretações do que vem a significar o termo "Empregabilidade", como, por exemplo, as duas a seguir:

Para Minvielle (1997), a empregabilidade é definida como:

[...] a capacidade de se auto-gerenciar, de administrar seu itinerário, seu percurso, e mesmo de o construir e dirigir. Pode ser entendida como a estrutura de competências que irá permitir a qualquer indivíduo assalariado manter-se no emprego [...] Pode-se, então, pensar que um pacto social de natureza nova pode ser acordado entre o 
empregador e o assalariado, para que o empresário se comprometa a manter e desenvolver a empregabilidade do assalariado (MINVIELLE, 1997, p. 179).

Já na interpretação de Minarelli (1995), empregabilidade é “[...] dar ou conseguir emprego para os seus conhecimentos, habilidades e atitudes intencionalmente desenvolvidos por meio de educação e treinamento sintonizados com as novas necessidades do mercado de trabalho" (MINARELLI, 1995, p. 11).

Com o advento da terceira revolução industrial e agora, mais recentemente, com o início da quarta revolução, adaptações e constante aprendizado tem se tornado cada vez mais necessários aos trabalhadores para que consigam estar sempre em condições de atender às demandas do mercado de trabalho. Por isso, segundo Moretto (2011), o rumo da educação passou a se embasar na aquisição de conteúdos para então permitir a aquisição de habilidades e competências na gerência dos conteúdos adquiridos.

Uma característica bastante necessária ao trabalhador atual é a flexibilidade, ou seja, é ter facilidade em abandonar conhecimentos prévios e aprender novas habilidades constantemente, quer dizer "aprender a aprender".

Seguindo essas mesmas ideias, Kessels (1997) afirma que:

[...] um sistema escolar geral eficiente, de alta qualidade, é um pré-requisito para a empregabilidade, e em nível global, fica claro que a formação é um elemento estratégico para o desenvolvimento profissional e pessoal dos trabalhadores e que também é um fator decisivo para a possibilidade de conseguir trabalho e a estabilidade, portanto o aprender a aprender é uma competência de valor e importância universais. Os indivíduos necessitam desta habilidade especial para a aprendizagem a fim de que possam permanecer inteirados das constantes mudanças que ocorrem nas condições de trabalho, e se tornarem "empregáveis" (KESSELS, 1997, p. 185 e 215).

\subsection{Estágio}

A formação técnica de um indivíduo não deve ter como foco uma atividade meramente operacional e mecanicista, mas um aprofundamento do fazer reflexivo e ativo por meio da interação e diálogo no meio em que vive.

Segundo Moretto (2011), a educação não se baseia mais apenas na aquisição de conteúdo, mas sim no desenvolvimento de habilidades e competências para que os alunos possam lidar com os conteúdos de maneira independente. Dessa forma, o autor também propõe que a educação seja voltada ao desenvolvimento de competências.

O estágio instiga o discente a desenvolver novas habilidades e competências conforme executa seu trabalho. Ou seja, segundo Buriolla (2011), o estágio é o período acadêmico do 
aluno, no qual sua identidade profissional é gerada, construída e referida; e tem como objetivo o desenvolvimento de uma ação vivenciada, reflexiva e crítica e, por isso, deve ser planejado gradativo e sistematicamente com essa finalidade. O estágio faz com que o aluno aplique o aprendizado teórico adquirido durante o curso para desenvolver habilidades práticas. Segundo Wagenaar et al. (2003), o estágio pode ser considerado o primeiro contato do estudante com o exercício de um ofício profissional e, dessa forma o estudante desenvolve aprendizados como gerenciamento de tempo, interação com colegas e supervisores num ambiente competitivo, resolução de problemas reais, entre outros.

Assim, o estágio passa a ser, também, uma ferramenta que possibilita a aproximação entre a escola, aluno, empresa e sociedade; contribuindo dessa forma no atendimento da demanda do mercado por profissionais cada vez mais competentes (MURARI; HELAL, 2009).

Nesse sentido, o estágio colabora com a atualização do currículo escolar, por isso, fica claro que a interação Empresa-Escola favorece ambas instituições, pois a partir do estágio a empresa passa a conhecer como a escola está capacitando seus futuros profissionais e a escola passa a ter um diagnóstico sobre se está formando seus alunos conforme as exigências do mercado.

\section{MATERIAL E MÉTODOS}

Para o levantamento da materialidade da pesquisa de campo foi enviado um formulário (Apêndice A), no primeiro semestre de 2020, para todos os ex-alunos formados até o ano de 2019, dos cursos técnicos (Integrado em Automação Industrial e Subsequente em Eletroeletrônica) do Campus Avançado Itabirito. Atualmente, o Campus oferta o curso Técnico Integrado em Automação Industrial e Engenharia Elétrica.

Os respondentes correspondem aos formandos do período de 2017 a 2019. A pesquisa foi conduzida utilizando-se do método misto concomitante que, segundo Creswell (2010), o investigador coleta os dados quantitativos e qualitativos ao mesmo tempo durante o estudo e depois integra as informações na interpretação dos resultados.

Dentre as estratégias relacionadas aos métodos mistos, a presente pesquisa utiliza-se da estratégia de triangulação concomitante, onde o pesquisador usa dois métodos diferentes a fim de confirmar, fazer validação cruzada ou corroborar resultados dentro de um único estudo (CRESWELL, 2010).

Para a análise quantitativa dos dados foi utilizada como referência a escala de Likert (1932), que, segundo Lopes, Shimoda e Shimoya (2013), é geralmente aplicada a pesquisas de 
satisfação, sendo sua estrutura mais comum baseada na existência de cinco itens: nota 1 - muito baixo; nota 2 - baixo; nota 3 - médio; nota 4 - alto; nota 5 - muito alto; $\mathrm{N}$ - não sei.

$\mathrm{Na}$ coleta de dados qualitativos, os alunos foram solicitados a apresentarem uma justificativa à algumas respostas fornecidas nas questões de caráter quantitativo. Dessa forma, segundo Creswell (2010), é possível aprofundar o entendimento da opinião gerada pela pesquisa e eliminar possíveis lacunas deixadas pela análise puramente quantitativa.

\section{RESULTADOS E DISCUSSÃO}

A seguir serão apresentadas as análises quantitativa e qualitativa utilizadas na pesquisa, ressaltando que em função do universo de 58 ex-alunos consultados (aproximadamente $30 \%$ de todos os técnicos formados), apenas dois respondentes fizeram estágio, por isso, para este caso, as Figuras com os dados foram suprimidos. Além disso, dentre os respondentes apenas dois são do curso técnico subsequente.

Embora o questionário também busque levantar informações sobre a influência do Exame Nacional do Ensino Médio (ENEM) na escolha dos estudantes pelo curso técnico integrado no IFMG, os alunos das modalidades integrado e subsequente foram inseridos na mesma pesquisa, uma vez que o objetivo principal deste trabalho é analisar o caráter profissionalizante dos cursos ofertados independente da modalidade.

\subsection{Análise Quantitativa}

Os resultados, na análise quantitativa, são apresentados de forma gráfica e as perguntas do questionário aplicado aos ex-alunos encontram-se na legenda das Figuras a seguir. 


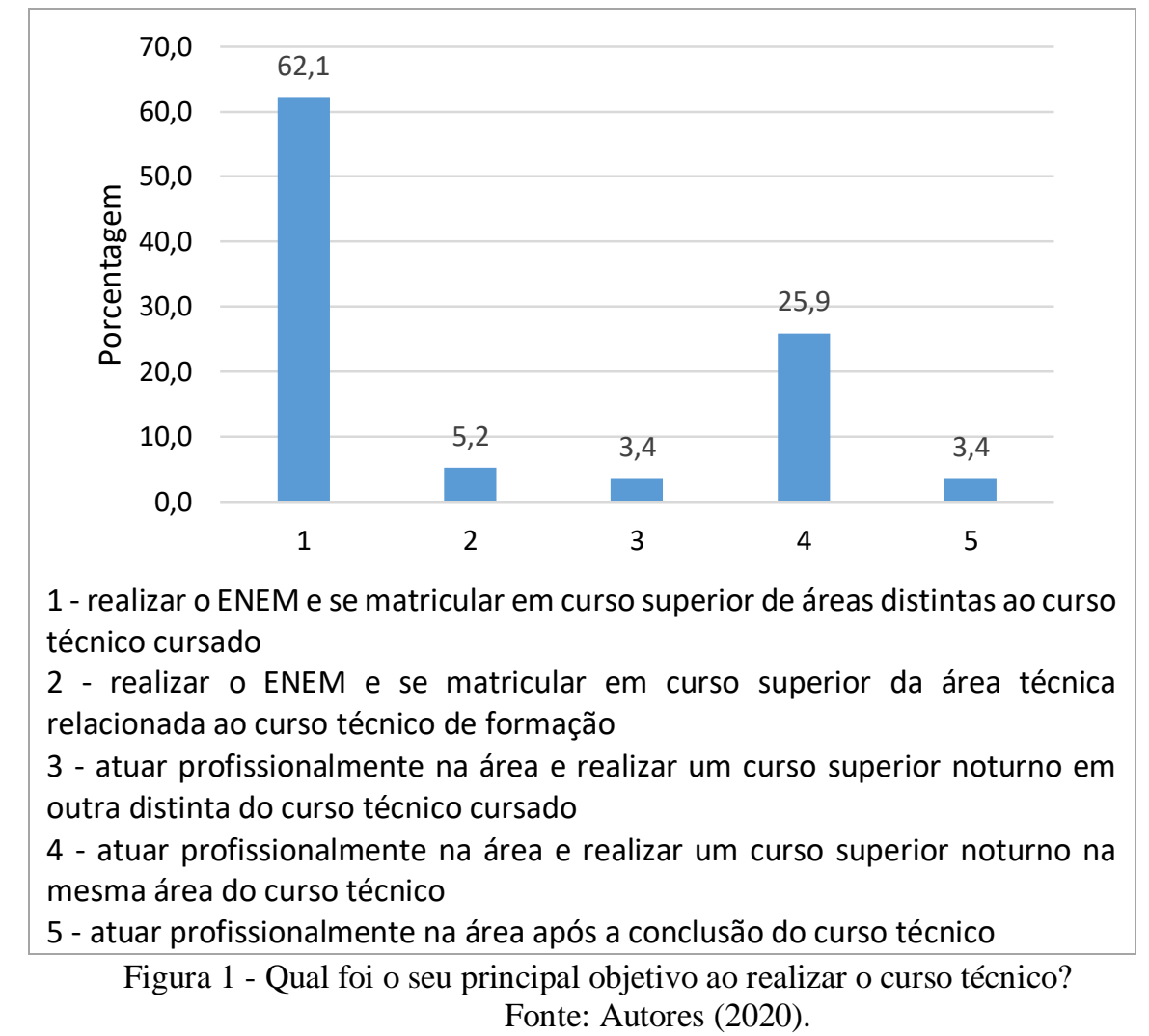

As opções de resposta do formulário para a pergunta 1, presentes na Figura 1, teve como justificativa os caminhos mais frequentes seguidos pelos alunos, do Campus em análise, após o ensino médio. Dessa forma, os alunos foram convidados a selecionar dentre essas opções a que mais se aproxima à sua realidade ao optar pelo curso, porém tais opções não necessariamente representam o objetivo principal do aluno pós formação técnica. Sendo assim, pela Figura 1 é possível identificar a percepção descaracterizada de um curso técnico profissionalizante por parte da comunidade, pois o somatório das respostas aos itens 1 e 2 computa $67,3 \%$ dos estudantes que optam pelo curso técnico integrado apenas para se preparar para o ENEM, sendo que $62,1 \%$ dos alunos manifestaram interesse em se matricular em cursos superiores distintos da área do curso técnico. O ótimo rendimento dos alunos dos institutos federais nas provas do ENEM (SALDAÑA; TAKAHASHI; GAMBA, 2018) justifica a alta procura dos estudantes pelos institutos com o objetivo de se preparar para o ENEM.

Porém, dentre os objetivos dos Institutos Federais, estabelecidos por meio do Artigo $7^{\circ}$ da Lei 11.892/2008, está "I - ministrar educação profissional técnica de nível médio, prioritariamente na forma de cursos integrados, para os concluintes do ensino fundamental e para o público da educação de jovens e adultos" (BRASIL, 2008). Sendo que a mesma Lei enfatiza a necessidade da garantia de no mínimo $50 \%$ das vagas para atender este objetivo (BRASIL, 2008). 
Portanto, o alto nível de procura dos cursos técnicos integrados em função do ENEM acaba distorcendo o público alvo proposto por esses cursos, já que a proposta de política pública dos Institutos Federais, além de outras, é promover a capacitação do profissional de nível técnico e consequentemente fomentar a verticalização da carreira profissional dos alunos.

Em continuação à análise quantitativa, foi pesquisada a opinião dos alunos sobre a atividade de estágio ser obrigatória no curso, considerando que atualmente esse não é um componente curricular obrigatório. De acordo com o parecer do CNE/CEB N 35 (2003), é facultado à instituição a obrigatoriedade da atividade de estágio (BRASIL, 2003). Conforme a Figura 2, o somatório dos respondentes das opções 3, 4 e 5 computa 63,8\% dos alunos que manifestaram ser pouco, parcialmente ou totalmente favorável à obrigatoriedade do estágio, o que demonstra a percepção dos alunos de certa importância da presença dessa atividade no currículo escolar.

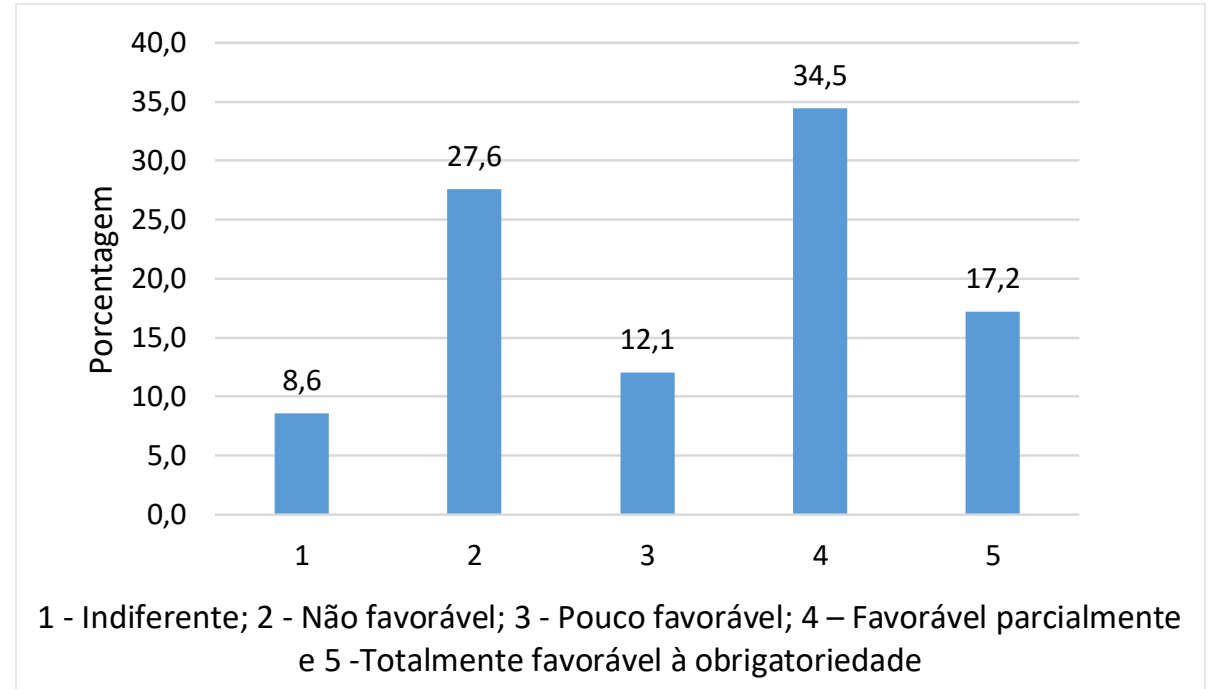

Figura 2 - Qual a sua opinião sobre a não obrigatoriedade do estágio no curso técnico? Fonte: Autores (2020).

\subsubsection{Alunos que fizeram estágio}

Além de fornecer uma vivência da teoria na prática, o estágio fornece ao estudante também uma experiência e aprendizado que não estão presentes na instituição de ensino. $\mathrm{O}$ trabalho em equipe proporciona ao aluno a oportunidade de experimentar a realidade social da profissão na qual está inserido. Por meio do estágio o aluno passa a conhecer a sua profissão, tendo contato diretamente com pessoas que possuem prática em exercê-la. No caso dos dois alunos que fizeram estágio, a atividade foi considerada, por eles, parcialmente favorável e essencial para a inserção no mercado de trabalho. 
A experiência de estágio vivenciada foi considerada por ambos satisfatória e, portanto produtiva com os profissionais da área. Sendo que nos dois casos a empresa manifestou possibilidade de efetivação, porém, apenas um deles está atualmente trabalhando na área de formação técnica.

\subsubsection{Alunos que não fizeram estágio}

A Figura 3 reforça o resultado apresentado na Figura 1. Dessa forma, pode-se corroborar a tese da descaracterização do curso técnico integrado profissionalizante, destacando-se mais uma vez a busca em grande maioria dos alunos pelo conteúdo propedêutico do curso, pois o baixo índice de procura do estágio demonstra o pouco interesse na formação profissionalizante de nível técnico por parte dos alunos.

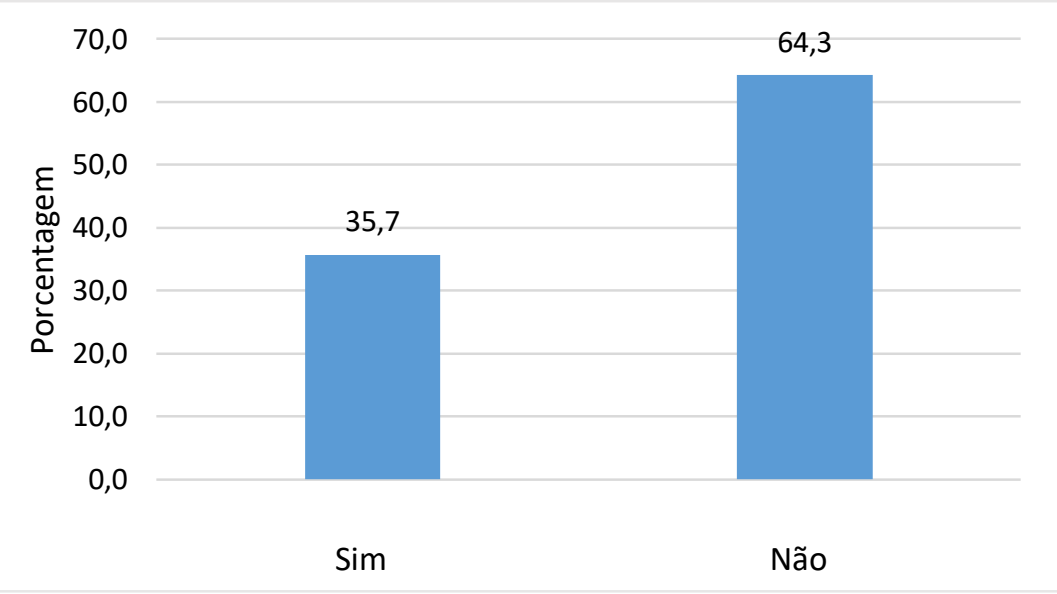

Figura 3 - Você buscou uma oportunidade de estágio de nível técnico em alguma empresa?

Fonte: Autores (2020).

A Figura 4 mostra que, como a busca da maior parte dos alunos é o melhor desempenho no ENEM para a conquista da vaga no ensino superior, é normal que $60,7 \%$ dos alunos não estejam trabalhando, levando-se em conta que estão frequentando, em sua grande maioria, cursos superiores de turno integral. Do total de ex-alunos que não estão trabalhando, 77\% estão realizando curso superior. 


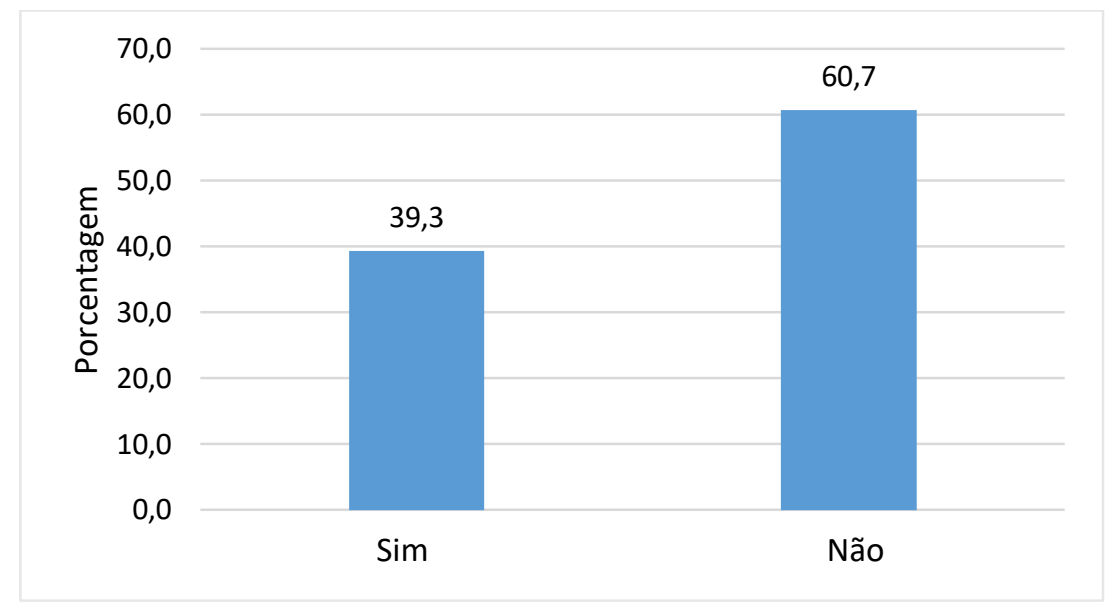

Figura 4 - Você está trabalhando de carteira assinada ou trabalhando de forma autônoma?

Fonte: Autores (2020).

Na Figura 5, o somatório dos respondentes dos itens 3, 4 e 5 indica que 59\% dos alunos manifestaram que o estágio, de alguma forma, fez falta na sua atuação como profissional de nível técnico. Essa informação reforça a importância do estágio no amadurecimento profissional dos alunos, a fim de melhor capacitá-los para atuarem no mercado de trabalho.

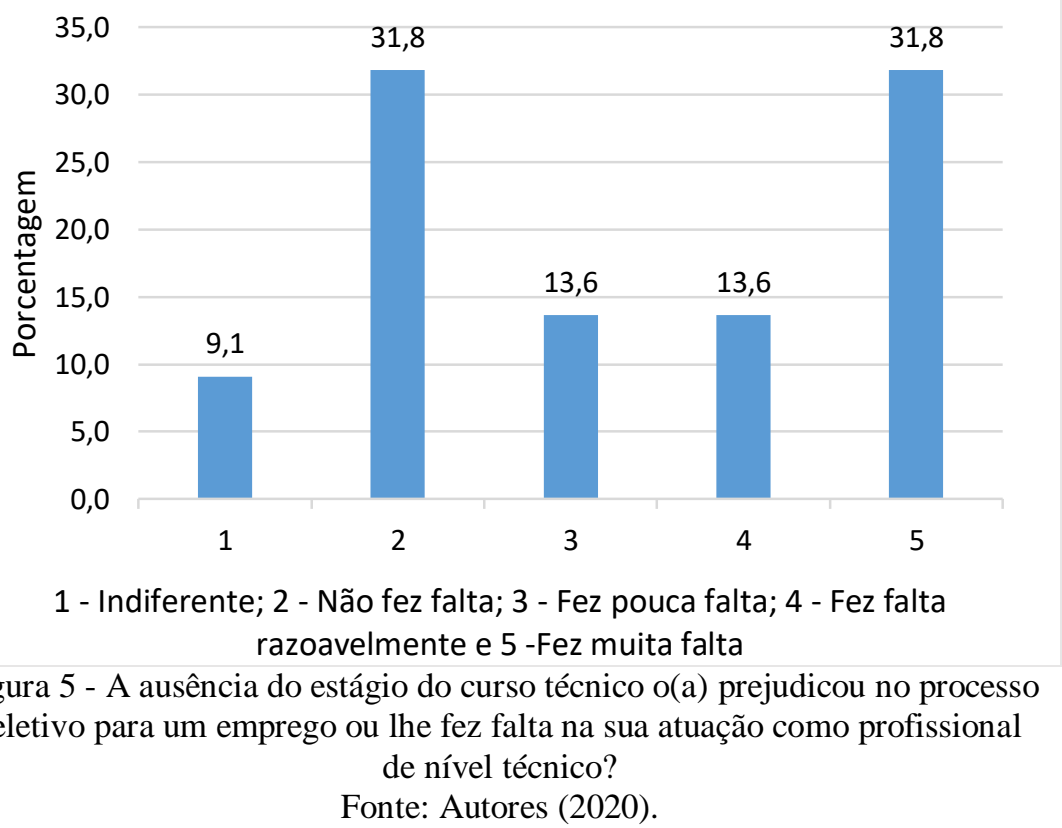

Na Figura 6, o grande volume de alunos cursando o ensino superior reforça os resultados das Figuras 1, 2 e 3. Ou seja, de maneira imediata ao fim do curso técnico em torno de $75 \%$ dos alunos estão cursando o ensino superior. Como dito anteriormente, ao considerarmos os exalunos que relataram não estar trabalhando, 77\% encontram-se matriculados em curso superior. 
Quando se trata de ex-alunos que relataram estar trabalhando, cerca de $70 \%$ destes trabalhadores estão realizando curso superior.

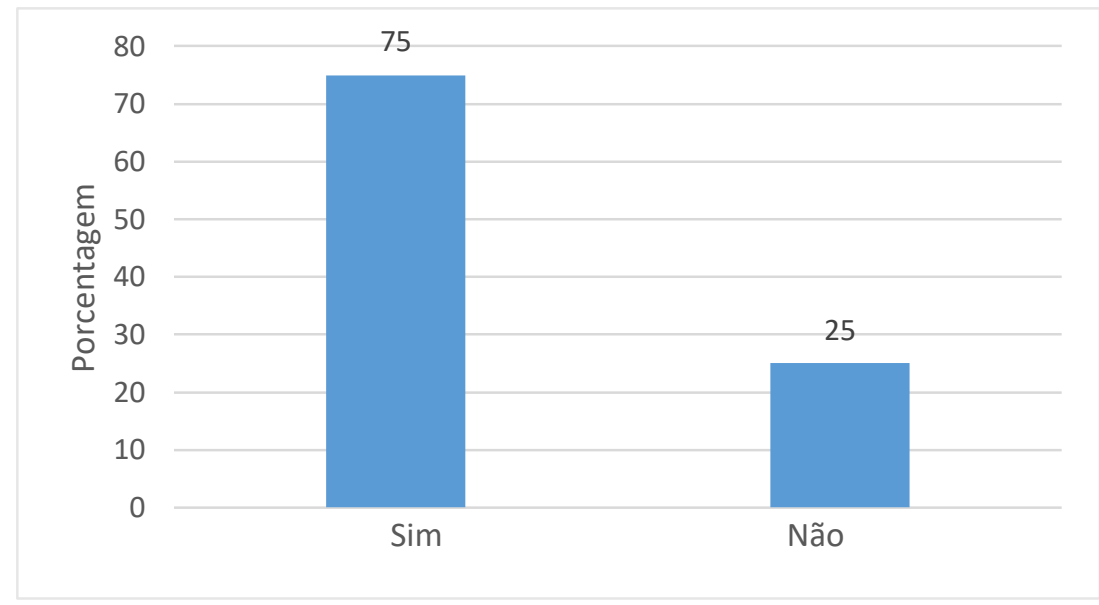

Figura 6 - Você está realizando ou realizou algum curso superior após a conclusão do curso técnico?

Fonte: Autores (2020).

\subsection{Análise Qualitativa}

Nas justificativas do questionamento "Qual a sua opinião sobre a não obrigatoriedade do estágio no curso técnico?" (Apêndice B), foram bastante frequentes justificativas relacionadas a quantidade de oportunidade, ou seja, vagas disponíveis; o tempo hábil para se realizar os estágios durante os três anos do ensino médio e também o motivo dos alunos optarem pelo ensino superior logo ao final do curso técnico. A Resolução CNE/CEB No 1 (2004) prevê que "O estágio deve ser realizado ao longo do curso, permeando o desenvolvimento dos diversos componentes curriculares e não deve ser etapa desvinculada do currículo" (BRASIL, 2004). Ou seja, o estágio deve ser realizado durante o aprendizado teórico do curso, dessa forma deixaria de ser um impeditivo aos alunos que optam por continuar sua jornada no ensino superior logo após o curso técnico. Niskier e Souza (2006) também defendem a presença concomitante do estágio com o curso técnico:

O estágio não substitui a aprendizagem escolar. Sua função é a de suplementar o conhecimento adquirido em sala de aula, vivenciando, na prática, o saber teórico que advém do conjunto de disciplinas do currículo de curso. [...]. Aqui surge uma primeira questão de interesse: o estágio deve corresponder sempre ao conteúdo de determinada disciplina curricular? É claro que não: sua função é holística e diz respeito ao conjunto de conhecimentos do curso como um todo. [...] A finalidade do estágio, pois, está na sua função auxiliar de inserir um aluno nas realidades extra-escolares do trabalho. Em razão dessa natureza pragmática não integra o estágio a estrita curricularidade deste ou daquele curso, devendo antes ser entendido como uma extensão do currículo e sua 
completação formativa, na capacitação de alunos para o trabalho (NISKIER; SOUZA, 2006, p. 125-126).

Com relação à quantidade de oportunidades, foi notória a presença da justificativa de que os alunos não optam pelo estágio, pois não conseguem vagas na área do curso, ou simplesmente não se interessam pela área. Porém, de acordo com Niskier e Souza (2006), a função do estágio é a de suplementar o aprendizado de sala de aula; além disso, ele possui função holística, funciona como um apoio importantíssimo ao curso como um todo.

Ou seja, o estágio não tem como função desenvolver estritamente habilidades técnicas, mas sim trazer ao aluno a oportunidade de conhecer o dia a dia do exercício de uma atividade laboral. Dessa forma, uma maior diversificação das áreas de atuação dos alunos no estágio pode favorecer uma ampliação da quantidade de vagas disponíveis. Assim, entende-se que os alunos devem ser orientados a procurar, inclusive, por vagas de estágio em áreas correlatas.

Considerando o curso técnico em automação industrial, por exemplo, do Campus Avançado Itabirito, os estudantes podem procurar oportunidades de estágio para atuarem, além da automação industrial, nas áreas de instalações elétricas, programação, manutenção de equipamentos, compra de produtos e peças, gestão de processos produtivos, etc. Com isso, as possibilidades de atuação se ampliam.

Sobre a queixa do tempo hábil para realizar o estágio dentro dos três anos de ensino médio, Moura (2010) relata sobre a " [...] necessidade de ampliação de carga horária do atual ensino médio majoritariamente proporcionado à população em até um ano letivo ou na intensificação da jornada escolar diária, [...]” (MOURA, 2010, p. 5).

Ou seja, pelo caráter do curso técnico integrado o período do ensino médio deve ser também diferenciado, para fortalecer o objetivo profissionalizante no discente e na instituição, pois é o estágio que aproxima e estreita a articulação entre a instituição de ensino, o aluno e o mercado de trabalho.

Ainda com base nas respostas apresentadas no Apêndice B, percebe-se com nitidez que apesar da maioria dos respondentes não concordarem com a obrigatoriedade do estágio no curso técnico integrado, especialmente por razões mencionadas anteriormente, uma parte significativa dos respondentes reconhecem que o estágio é importante em sua formação profissional.

No questionário aplicado, os ex-alunos que informaram estar realizando curso superior foram solicitados a indicar o curso e o ano de ingresso (Apêndice C). Dentre eles, mais de 50\% optaram em realizar cursos da área de tecnologia e, dentre esses 22 respondentes, 12 estão 
matriculados em cursos relacionados a sua formação técnica (Engenharia Elétrica, Engenharia de Controle e Automação, Mecatrônica, etc.).

Levando-se em conta a diversidade natural de afinidades e interesses dos formandos, considera-se ainda significativo o percentual de formandos que optaram por continuar sua formação em áreas correlatas à sua formação técnica.

\section{CONCLUSÃO}

Os dados coletados nos levam a algumas conclusões que dizem respeito não apenas ao curso oferecido, mas também ao contexto socioeconômico e educacional local. Apesar de ficar evidente que a maioria dos alunos que optam e são aprovados no curso tecnológico não estão necessariamente interessados em atuar na área técnica, percebe-se que o curso provavelmente influenciou boa parte deles, já que os cursos superiores na área de ciências exatas tiveram preponderância nas escolhas aos que ingressaram posteriormente no ensino superior. Isto significa que, apesar dos fracos resultados de experiência prática e empregabilidade imediata, apenas de nível técnico, percebem-se resultados expressivos no interesse de desenvolvimento e formação posteriores por parte dos egressos.

Deve-se levar em consideração também que o curso técnico integrado oferecido pelo IFMG - Campus Avançado Itabirito tem dois diferenciais que tendem a atrair os estudantes em geral que residem na cidade e região: 1. Tem apresentado os melhores resultados de desempenho no ENEM (sendo assim, mais disputados por quem pretende ingressar posteriormente em um curso superior, principalmente na área de ciências exatas), 2. É um curso público e gratuito, o que trata-se de um enorme diferencial socioeconômico, atraindo estudantes que, apesar de não terem interesse específico pela formação ou experiência técnica, não têm condições de cursar escolas particulares de boa qualidade e não confiam na formação das escolas estaduais e municipais da região (que apresentam desempenhos sensivelmente inferiores ao IFMG no ENEM).

Sugere-se um trabalho de aproximação maior entre a instituição, empresas, organizações não governamentais (ONGs) e órgãos públicos da região de Itabirito, no sentido de estabelecer mais canais interativos, visitas técnicas e eventos que promovam um relacionamento mais próximo e efetivo de professores, alunos e o mercado de trabalho em suas diversas modalidades. Sugere-se também uma ação institucional, no sentido de adequar a duração do curso e/ou carga horária letiva, a fim de fomentar as oportunidades de estágio para os alunos. Ainda pensando numa ação institucional, sugere-se o movimento de conscientizar os 
estudantes sobre as possíveis vagas de estágio que podem atuar, para que não aconteça de buscarem vagas estritamente relacionadas à Automação Industrial ou Eletroeletrônica, e dessa forma, as oportunidades de atuação se ampliarem.

Uma hipótese que talvez explique o baixo grau de oferecimento de estágios na região para os discentes do curso integrado de nível médio é o fato de ele se concentrar em uma área relacionada à formação do curso superior em Engenharia Elétrica, oferecido pelo mesmo Campus além de outros cursos superiores como Engenharia de Controle e Automação oferecido pela UFOP, em Ouro Preto. Talvez as vagas ofertadas estejam sendo ocupadas por alunos desses outros cursos, pois os empregadores tenderiam a dar preferência a um estagiário graduando do que a um cursando ainda no nível médio. Para verificarmos esta hipótese, teríamos, porém, que realizar uma nova etapa desta pesquisa, no sentido de captar a realidade dos egressos dos cursos superiores na área correlata ofertados na região de Itabirito, o que pode ser a proposta para um desdobramento deste trabalho. Assim como a ampliação do horizonte de pesquisa incluindo consultas a empresas e instituições locais, bem como, consultas aos docentes dos cursos e à gestão do Campus, é percebida pelos autores como ações potenciais para uma caracterização mais aprofundada sobre o tema empregabilidade dos egressos dos cursos.

Pensando em longo prazo, na medida em que o Campus Avançado Itabirito for ampliado, possibilitando o oferecimento de um número maior de cursos, sugere-se a diversificação desses cursos de nível técnico, contemplando outras áreas do saber (Ciências Humanas, Gerenciais e Biológicas), no sentido de a instituição abarcar a diversidade de oportunidades de emprego e afinidades pessoais dos candidatos. Dessa forma, haverá um filtro baseado na aptidão e interesse dos candidatos antes mesmo que ingressem nos cursos, ampliando suas futuras áreas de atuação. É claro que esse processo demandará contratações e ampliação da estrutura física e técnica do Campus, porém, acreditamos que é uma forma de, ao mesmo tempo, adaptá-lo melhor às demandas locais e fomentar inclusive a transdisciplinaridade entre tais áreas, o que também é aconselhável no sentido de fornecer uma formação mais generalista e holística do saber.

Os autores do trabalho continuam nesta linha de investigação, com o objetivo de uma melhor caracterização da empregabilidade dos ex-alunos, relacionando as habilidades desenvolvidas durante a sua formação técnica em favor da sua atividade laboral, mesmo que não seja estritamente relacionada à área de sua formação. Num discurso mais generalista de competências e habilidades, acredita-se que tais jovens possuem boa competitividade no mercado de trabalho quando comparados aos jovens de formação básica apenas. 


\section{REFERÊNCIAS}

BRASIL. Lei n⿳ 11.892, de 29 de dezembro de 2008. Institui a Rede Federal de Educação Profissional, Científica e Tecnológica, cria os Institutos Federais de Educação, Ciência e Tecnologia, e dá outras providências. Brasília, DF: Presidência da República, 2008. Disponível em: http://www.planalto.gov.br/ccivil 03/ Ato2007-2010/2008/Lei/L11892.htm. Acesso em: 17 nov. 2020.

BRASIL. Ministério da Educação. Parecer CNE/CP No: 35/2003, de 05 de Novembro de 2003. Normas para a organização e realização de estágio de alunos do Ensino Médio e da Educação Profissional. Brasília, 2003 Disponível em: http://portal.mec.gov.br/cne/arquivos/pdf/pceb35_03.pdf. Acesso em: 17 nov. 2020.

BRASIL. Ministério da Educação. Resolução CNE/CEB No: 1/2004, de 21 de janeiro de 2004. Estabelece Diretrizes Nacionais para a organização e a realização de Estágio de alunos da Educação Profissional e do Ensino Médio, inclusive nas modalidades de Educação Especial e de Educação de Jovens e Adultos. Brasília, 2004. Disponível em: http://portal.mec.gov.br/seesp/arquivos/pdf/res1.pdf. Acesso em: 17 nov. 2020.

BURIOLLA, M. A. F. O estágio supervisionado. 7 ed. São Paulo: Cortez, 2011.

CRESWELL, J. W. Projeto de pesquisa: métodos qualitativo, quantitativo e misto. 3 ed. Porto Alegre: Artmed, 2010.

CASTRO, J.; PONTE, G. Mesmo com reformas, Brasil ainda crescerá menos que emergentes. Reuters, 6 dez. 2019. Negócios. Disponível em: https://br.reuters.com/article/businessNews/idBRKBN1YA26S-OBRBS. Acesso em: 17 nov. 2020.

CARDOSO, K. Jovens são os mais afetados pelo desemprego. Você S/A, 23 fev. 2018. Disponível em: https://vocesa.abril.com.br/geral/jovens-sao-os-mais-afetados-pelodesemprego/. Acesso em: 17 nov. 2020.

KESSELS, J. W. M. A produtividade do conhecimento e o currículo corporativo. In: CASALI, A. et al. (Org.). Empregabilidade e educação: novos caminhos no mundo do trabalho. São Paulo: EDUC, 1997.

LIKERT, R. A technique for the measurement of attitudes. Archives of Psychology, 1932.

LOPES, T. N. L. S.; SHIMODA, E.; SHIMOYA, A. Estágio supervisionado: percepções dos concluintes de um curso técnico de enfermagem de uma instituição estadual de ensino de Campos dos Goytacazes. Acta Biomedica Brasiliensia, Rio de Janeiro, 2013. Disponível em: https://www.actabiomedica.com.br/index.php/acta/article/view/66/39. Acesso em: 17 nov. 2020.

MINVIELLE, Y. Auto-formação e socialização. In: CASALI, A. et al. (orgs.). Empregabilidade e educação: novos caminhos no mundo do trabalho. São Paulo: EDUC, 1997. 
MINARELLI, J. A. Empregabilidade: o caminho das pedras. São Paulo: Gente, 1995.

MORETTO, V. P. Construtivismo: a produção do conhecimento em aula. Rio de Janeiro: Lamparina, 2011.

MOURA, D. H. Algumas possibilidades de organização do ensino médio a partir de uma base unitária: trabalho, ciência, tecnologia e cultura. SEMINÁRIO NACIONAL: currículo em movimento: perspectivas atuais Belo Horizonte, nov. de 2010. Disponível em: http://portal.mec.gov.br/docman/dezembro-2010-pdf/7177-4-2-algumas-possibilidadesorganizacao-ensinomedio-dante-henrique/file. Acesso em: 17 nov. 2020.

MURARI, J. M. F.; HELAL, D. H. O estágio e a formação de competências profissionais em estudantes de Administração. Revista Gestão e Planejamento, Salvador, v. 10, n. 2, p. 262280, 2009. Disponível em: http://www.spell.org.br/documentos/ver/832/o-estagio-e-aformacao-de-competencias-profissi. Acesso em: 17 nov. 2020.

NISKIER, A.; SOUZA, P. N. P. Educação, estágio e trabalho. São Paulo: Integrare, 2006.

RAMOS, M. N. História e política da educação profissional. Coleção Formação Pedagógica, v. 5. Instituto Federal do Paraná, Curitiba, 2014.

SALDAÑA, P.; TAKAHASHI, F.; GAMBA, E. Institutos federais lideram nota do Enem em 14 Estados. Gazeta do Povo, 2018. Disponível em:

https://www.gazetadopovo.com.br/educacao/institutos-federais-lideram-nota-do-enem-em-14estados-83ypmfzthn6gx8v8npmb7fa71/. Acesso em 23 de dezembro de 2020.

WAGENAAR, A. et al. The importance of active involvement in learning: a qualitative study on learning results and learning processes in different traineeships. Advances in Health

Sciences Education, Netherland v. 8, n. 2, p. 201-212, 2003. Disponível em: https://www.researchgate.net/publication/5414077 The Importance of Active Involvement _in_Learning_A_Qualitative_Study_on_Learning_Results_and_Learning_Processes_in_Diffe rent Traineeships. Acesso em: 17 nov. 2020.

\section{APÊNDICE A - FORMULÁRIO (PERGUNTAS)}

1. Qual foi o principal objetivo com o curso técnico?

2. Você está realizando ou realizou algum curso superior após a conclusão do curso técnico?

3. Qual o curso superior e ano de ingresso?

4. Você realizou estágio supervisionado de nível técnico durante ou após concluir o curso técnico?

5. Na sua opinião, o estágio favorece a sua inserção no mercado de trabalho?

6. A realização do estágio favoreceu a vivência da teoria do curso na prática? 
7. Justifique a resposta da questão anterior indicando quais as disciplinas cursadas que você acredita terem sido úteis na realização do estágio.

8. Na realização do estágio do curso técnico, como julga o intercâmbio ou interação com o(s) profissional(ais) da área?

9. Durante a realização do estágio, a empresa demonstrou possibilidades de efetivação?

10. Você está trabalhando na área de sua formação técnica?

11. O estágio do curso técnico realizado favoreceu de alguma forma a sua colocação no mercado?

12. O estágio contribuiu de alguma forma para incentivá-lo à empreender e abrir um próprio negócio? Ou trabalhar de maneira autônoma?

13. Você buscou uma oportunidade de estágio de nível técnico em alguma empresa?

14. Você está trabalhando de carteira assinada ou trabalhando de forma autônoma?

15. Nos processos seletivos, entrevistas para emprego como técnico ou abertura de um negócio, a falta da experiência do estágio do curso técnico o(a) prejudicou no seu posicionamento no mercado de trabalho?

16. A ausência do estágio do curso técnico o(a) prejudicou no processo seletivo para um emprego ou lhe fez falta na sua atuação como profissional de nível técnico?

17. Qual a sua opinião sobre a não obrigatoriedade do estágio no curso técnico?

18. Justifique, por favor, a questão anterior.

\section{APÊNDICE B - Qual a sua opinião sobre a não obrigatoriedade do estágio no curso} técnico?

Acho indiferente, pois cabe ao aluno a escolha e ao instituto recomendar o estágio apenas aos alunos que realmente têm interesse de seguir a carreira técnica.

Apesar de entender que é muito difícil em uma cidade pequena conseguir um estágio bom para uma turma de aproximadamente 30 pessoas, mas acredito que seria ótimo para a capacitação profissional de cada um. Cada conceito, práticas, sendo possível ser visualizado em uma empresa, ajuda muito a agregar conhecimento. O convívio com os profissionais da área ajuda no amadurecimento, ajuda a enxergar você naquele local, se é isso mesmo que cada um quer para o futuro. E sem contar que é uma oportunidade de ouro para ingressar no mercado de trabalho. Portanto, em minha opinião os ganhos são imensuráveis. Somente 
agradeço a escola pela oportunidade e aos professores que dividiram seus conhecimentos de forma clara e nas condições possíveis da atual infraestrutura.

A obrigatoriedade do estágio agregaria consideravelmente na consolidação do aprendizado técnico adquirido durante a realização do curso (o que eu sinto bastante falta hoje). Porém, a indisponibilidade de vagas para todos os discentes seria um problema a ser enfrentado. Além disso, necessitaria de um apoio do campus para o direcionamento dos alunos para o estágio. Por esses motivos, sou parcialmente favorável à obrigatoriedade.

Eu acho o ensino do instituto muito bom, mas as empresas não dão muita oportunidade É muito importante, pois ele contribui para vermos na pratica o que foi aprendido, além de agregar experiência ao nosso currículo.

$\mathrm{Na}$ minha opinião, de nada adianta estudar um curso técnico durante 3 anos e depois, simplesmente começar a estudar outras coisas. Já esqueci praticamente tudo que aprendi no IF pois, não coloquei em prática suficientemente

O estágio lhe coloca frente a um ambiente de trabalho propriamente dito, coisa que somente com a prática do TCC não conseguimos ter acesso. Além disso é ótimo para consolidar o aprendizado em sala de aula e agregar ainda mais profissionalmente.

Estágio é essencial pra colocar nosso conhecimento em prática, ter o contato do tipo de trabalho que vamos lidar e já chegar preparado e além do mais a possibilidade de já sair efetivado no estágio é muito grande.

Prepara o aluno para o mercado, além de conciliar em suas futuras escolhas

Muito importante na formação dos alunos

Acredito que o estágio constitui o primeiro passo para o mercado de trabalho. Proporciona o desenvolvimento de habilidades como a atitude, coletividade e o mais importante... O primeiro contato com a área. Sabemos que muitas empresas infelizmente exigem experiência de trabalho para ocupar certa vaga, considerada primária para a área em questão. O estágio pode servir para substituir tal requerimento, claro, sendo realizado cumprindo requisitos adequados.

Eu não passei pelo estágio e senti que aprendi muito sobre o curso realizando o TCC

É através do estágio que o aluno consegue ter a real visão do mercado de trabalho, na prática! Devido a quantidade de alunos cursando Automação Industrial vs. a oportunidade de estágio em Itabirito e região. Acredito que o TCC seja a melhor opção, tanto para aqueles que desejam seguir na área quanto para os que não desejam, pois é uma maneira de "compilar" os conhecimentos adquiridos. A obrigatoriedade, ao meu ver, faria com que houvessem mais 
desistências por causa da dificuldade em encontrar um estágio. Devem ser opcionais para aqueles que querem seguir na área e/ou tem disponibilidade para fazer um estágio que pode não ser remunerado. Mas seria legal se o mercado de trabalho conseguisse nos absorver e facilitar esse processo.

O estágio deve ser exigido sempre que haver vagas disponíveis proposta pela instituição de ensino. Sei como é difícil conseguir um estágio de nível técnico, o aluno que se dedica indo as aulas não pode ser prejudicado por não conseguir fazer um estágio

A obrigatoriedade do estágio deve ser para os alunos do técnico que querem seguir a profissão ou que irão cursar graduação no mesmo ramo. Os demais, na minha opinião, devem se graduar e seguir logo a profissão da qual almejam.

Não sou favorável à obrigatoriedade do estágio técnico, pois muitas vezes os alunos não se interessam em permanecer na área técnica, visando a entrada no curso superior logo de imediato à formação do ensino médio.

Tem poucas vagas de estágio.

É importante que o aluno tenha contato com o que foi aprendido de forma prática, porém, de forma obrigatória no caso de alunos que não queiram seguir o ramo, torna-se um peso no curso. Dessa maneira, pode ser que o aluno não tire o proveito necessário e até mesmo tente burlar o estágio. Este somente para os que desejarem seria melhor aproveitado.

Totalmente favorável, pois além de praticar o que se aprendeu, é também uma oportunidade de se inserir no mercado de trabalho.

Durante a realização do curso não tem tempo hábil para a realização do estágio O estágio seria interessante pra podermos aprender na pratica sobre automação. Porém seria difícil conseguir estagio pra todos, o que poderia ser ruim.

O estágio do curso técnico na minha opinião deveria ser mais valorizado no técnico, deveria surgir oportunidades para os alunos que querem seguir na área ou que querem explora-la, não deveria ser totalmente obrigatória mas deveria ter oportunidades e suporte para aqueles que desejam realizar o estágio.

Para quem pretende seguir na área, penso que o estágio é uma forma de relembrar os ensinamentos do técnico e uma ótima base para um emprego ou até mesmo para um curso superior na área. De qualquer forma, vejo um estágio como uma oportunidade de colocar em prática o que foi aprendido

Acredito que uma parcela significativa dos alunos que ingressam no curso técnico não possuem interesse exclusivo em atuar como técnicos 
Acredito importante a realização do estágio, até mesmo para quem não queria seguir, uma vez que a prática é diferente e pode mudar em alguma das nossas percepções. Entretanto, na região ainda não há muita oportunidade de estagio, então acredito que isso possa criar um empecilho na formação para aquelas pessoas que não tem condições de sair da região.

O estágio supervisionado é de grande importância para a formação profissional do aluno, de modo que proporciona a vivência de práticas do ambiente de trabalho relacionado ao curso de sua escolha. Particularmente, não procurei estágio quando me formei, meu foco era iniciar um curso superior em uma área distinta. Porém, atualmente eu percebo que essa oportunidade seria fundamental para as minhas experiências na Automação. Portanto, acredito que o estágio não deva ser obrigatório (visto que muitos alunos têm interesse maior na qualidade do ensino médio da instituição, analisando um contexto geral de nossa cidade). Mas acredito que ele deva ser estimulado através de parcerias do instituto com empresas locais, etc. Assim, as chances dessas pessoas se interessarem pela carreira e continuarem no ramo é maior. Como membro da primeira turma de automação do campus, percebo que pouquíssimos colegas continuaram na área.

Pois as empresas hoje cobram muito em relação a experiência comprovada em carteira assinada como profissional da área.

Alguns alunos não tem interesse em seguir carreira, portanto o estágio obrigatório não seria interessante

Todo o processo do terceiro ano já é cansativo com o TCC, se o estágio fosse obrigado seria extremamente maçante para os alunos. Se for depois para tirar o técnico acho injusto, porque a pessoa já se dedicou bastante para desenvolver suas habilidades no trabalho de conclusão de curso. Se não houvesse TCC, talvez fosse uma opção. No meu caso, o TCC me agregou MUITO conhecimento, inclusive que eu não tinha aprendido. Talvez pudesse ser opcional ao aluno fazer o TCC e sair com o técnico ou sair com o técnico pendente na condição de fazer um estágio

Como experiência profissional, é uma excelente oportunidade, pois sendo obrigatório as empresas são mais abertas a participação dos estudantes. Mas apesar do estágio ser muito importante para facilitar o ingresso no mercado de trabalho, ele pode ser complicado para aqueles que ingressaram na faculdade, devido a falta de tempo e disponibilidade para trabalhar e estudar simultaneamente e por causa disso acabar perdendo o diploma de técnico seria uma pena. 
Nem todos os alunos que fazer o curso pretendem seguir na área de automação, mas alguns pretendem continuar e o estágio (experiência) é um diferencial na hora de buscar por uma oportunidade de emprego na área.

No meu ponto de vista, o estágio dá um novo olhar em questão do trabalho e mostra como podemos colocar os aprendizados em prática. Porém não sou favor pela obrigatoriedade, pois deve se fazer pela própria vontade.

Pra quem quer seguir a área seria de extrema importância, mas para quem não vai seguir a área não faria diferente

Não acho necessário um estágio!

Ao iniciar o curso, os alunos não sabem realmente do que se trata. Provavelmente na conclusão, mais da metade vão querer seguir outra profissão. Desta forma, o estágio não deve ser obrigatório, pois, quem quiser seguir na área pode correr atrás e fazer o estágio, já quem não quer está livre pra seguir em frente.

Acredito que o incentivo ao estágio deve ser defendido, mas não sua obrigatoriedade.

Embora ainda não confirmada por muitos estudos, estamos suscetíveis à Quarta Revolução Industrial, haja vista que essa mesma revolução garante mais autonomia aos processos industriais. Dessa forma, acredito que as vagas, mesmo aquelas destinadas a estágios, possam ser afetadas em relação a quantidade ofertada. Assim, se não houver vaga suficiente, não há o porquê de o estágio se tornar obrigatório.

Acho importante o aluno ter uma experiência prática com o curso técnico fazendo um estágio, pois assim ele poderá ter a certeza se deseja seguir na área ou não. Ao mesmo tempo acredito que somente o curso por si só pode fazer com que alguns alunos já saibam se gostam da área e quer seguir em frente ou não, então a total obrigatoriedade pode se tornar algo indesejável e cansativo. Acho que a ideia do aluno poder decidir se quer fazer ou não é a melhor alternativa.

É um bom preparo profissional para o indivíduo

É importante a disponibilidade de um estágio para a prática dos conhecimentos realizados em aula no ambiente correspondente ao de trabalho, porém a obrigatoriedade pode acabar por transformar esta experiência em algo desagradável ou desconfortável, especialmente para os alunos que não pretendem seguir na área como um profissional.

Pelo fato de muitas pessoas acabam não gostando daquela formação Não há necessidade, visto que a maioria dos alunos não procuram o If pelo curso técnico e sim pelo ensino médio. Logo, são poucos que irão atuar na área. 
Creio que a obrigatoriedade não seja o caminho, e sim a divulgação das vagas por parte da instituição incentivando assim, os alunos a buscarem uma oportunidade.

A obrigatoriedade do estágio no curso técnico seria uma boa opção, pois iria aproximar mais os alunos da realidade no âmbito profissional a área.

Não sou favorável a obrigatoriedade porque o IFMG Itabirito ainda é um Campus em avanço que não proporciona aos secundaristas uma variabilidade de possibilidades de cursos, consequentemente não atende a todas as áreas de interesse e atuação dos secundaristas.

Acho que principalmente na região que estamos não haveria estágios de automação industrial a todos os alunos, mas sou a favor de ser obrigatório se fosse outro curso com a quantidade exata ou maior de estágios.

Muitos alunos fazem o curso, mas não possuem interesse em seguir na área. Dessa forma, acredito que seria mais proveitoso a realização do estágio de maneira optativa.

No meu caso não foi imprescindível para conseguir um emprego

Poderia se ter a opção de trocar o Tcc pelo estágio.

O estágio possibilitaria aos alunos entender o seu papel com técnico em Automação e como realmente atuariam no mercado de trabalho. Preparando assim os alunos e tornando-os aptos a exercer a profissão.

Não favorável a obrigatoriedade, mas favorável ao incentivo das instituições para que os alunos realizem o estágio.

Porque acaba que a gente não aplicou de fato os conhecimentos adquiridos durante o curso, não fazendo o estágio a gente não descobre se realmente queremos atuar na área posteriormente

Não sei opinar, não sinto falta porém as vezes acho necessário

Acredito que o estágio pode transmitir mais confiança e experiência ao aluno que possui interesse de atuação na área. Entretanto, para alunos que não se identificam, o estágio pode se tornar um problema. Dessa forma, uma das melhores soluções é a realização de trabalhos, como o TCC, que exijam do aluno prática e domínio do curso. Tornando assim o estágio não obrigatório, mas sendo uma opção para alunos que optarem por ele.

Auxiliaria a colocar o aprendido em sala de aula em prática

O estágio ajuda a dar experiência, apesar da qualidade do ensino ofertada pelo IFMG 


\section{APÊNDICE C - Qual curso superior e qual ano de ingresso? (42 respostas)}

\begin{tabular}{|c|c|c|}
\hline \multirow{6}{*}{ Humanas } & Arquitetura e Urbanismo, 2018 & \multirow{6}{*}{$14,3 \%$} \\
\hline & Arquitetura e Urbanismo, 2019 & \\
\hline & Biblioteconomia, 2020 & \\
\hline & Educação Física, 2019 & \\
\hline & Gestão pública,2019 & \\
\hline & Pedagogia, 2018 & \\
\hline \multirow{14}{*}{ Saúde } & Biomedicina, 2018 & \multirow{14}{*}{$33,3 \%$} \\
\hline & Enfermagem e obstetrícia, 2020 & \\
\hline & Farmácia, 2018 & \\
\hline & Farmácia, 2019 & \\
\hline & Farmácia, 2019 & \\
\hline & Farmácia, 2019 & \\
\hline & Fisioterapia, 2018 & \\
\hline & Fisioterapia, 2019 & \\
\hline & Fisioterapia, 2020 & \\
\hline & Medicina Veterinária, 2018 & \\
\hline & Medicina, 2018 & \\
\hline & Nutrição, 2018 & \\
\hline & Odontologia, 2020 & \\
\hline & Odontologia, 2020 & \\
\hline \multirow{13}{*}{ Tecnologia } & Agronomia, 2019 & \multirow{13}{*}{$52,4 \%$} \\
\hline & Engenharia ambiental, 2020 & \\
\hline & Engenharia civil, 2018 & \\
\hline & Engenharia Civil, 2018 & \\
\hline & Engenharia Civil, 2019 & \\
\hline & Engenharia de Controle e Automação, 2018 & \\
\hline & Engenharia de Controle e Automação, 2018 & \\
\hline & Engenharia de Controle e Automação, 2019 & \\
\hline & Engenharia de Controle e Automação, 2020 & \\
\hline & Engenharia de Controle e Automação, 2020 & \\
\hline & Engenharia de Produção, 2018 & \\
\hline & Engenharia Elétrica, 2018 & \\
\hline & Engenharia elétrica, 2019 & \\
\hline
\end{tabular}




\begin{tabular}{|l|l|}
\hline & Engenharia Elétrica, 2019 \\
\cline { 2 - 3 } & Engenharia Elétrica, 2020 \\
\cline { 2 - 3 } & Engenharia Elétrica, 2020 \\
\cline { 2 - 3 } & Engenharia mecatrônica, 2019 \\
\cline { 2 - 3 } & Engenharia Urbana, 2018 \\
\cline { 2 - 3 } & Química Industrial, 2019 \\
\cline { 2 - 3 } & Química, 2018 \\
\hline & Química, 2019 \\
\cline { 2 - 3 } & Sistemas de informação, 2020 \\
\hline
\end{tabular}

\section{DADOS DOS AUTORES:}

\section{Cleverson Faria de Oliveira}

E-mail: cleverson.oliveira@ ifmg.edu.br

Curriculum Lattes: http://lattes.cnpq.br/7060392775986124

Mestrado em Engenharia Elétrica pela Universidade Federal de Itajubá; especialização em docência pelo Instituto Federal de Minas Gerais; e graduação em Engenharia Elétrica com Ênfase em Eletrônica pela Universidade Federal de Itajubá e Aprendizagem Industrial em Eletroeletrônica pelo SENAI. É docente no Instituto Federal de Minas Gerais - Campus Avançado de Itabirito. Área de Atuação: Eletrônica e Sistemas Embarcados.

\section{Cláudia Rejane de Mesquita}

E-mail: claudia.mesquita@ifmg.edu.br

Curriculum Lattes: http://lattes.cnpq.br/7762631944977749

Doutorado e mestrado em Engenharia Elétrica pela Universidade Federal de Minas Gerais e graduação em Engenharia Elétrica pelo Centro Federal de Educação Tecnológica de Minas Gerais. Atualmente é docente e coordena o curso de Bacharelado em Engenharia Elétrica no Instituto Federal de Minas Gerais - Campus Avançado Itabirito. Tem experiência na área de Engenharia Elétrica, com ênfase em Sistemas Elétricos de Potência e Eletromagnetismo.

\section{Venilson Luciano Benigno Fonseca}

E-mail: venilson.luciano@ifmg.edu.br

Curriculum Lattes: http://lattes.cnpq.br/4392452858016775

Doutorado, mestrado e graduação em Geografia Humana pela Universidade Federal de Minas Gerais. Graduando em Direito pela Faculdade de Direito de Conselheiro Lafaiete. Docente do Curso de Licenciatura em Geografia, na Pós-Graduação em Docência do Instituto Federal de Minas Gerias e no Programa de Pós-Graduação em Ensino de Geografia em Rede Nacional (PROFGEO) - Mestrado. Pesquisa temas relacionados à produção do espaço e ordenamento territorial, além de temáticas ligadas à educação, ensino de geografia e Direito Público. 